\title{
Health related quality of life (HRQoL) and its associated surgical factors in diabetes foot ulcer patients
}

\author{
Heeya Shah ${ }^{1}$, Rima Shah ${ }^{2}$, Hiren Sanghani ${ }^{3}$, Niyati Lakhani ${ }^{4}$ \\ ${ }^{1}$ GMERS MEDICAL COLLEGE, GANDHINAGAR, GUJARAT, INDIA \\ ${ }^{2}$ DEPARTMENT OF PHARMACOLOGY, GMERS MEDICAL COLLEGE, GANDHINAGAR, GUJARAT, INDIA \\ ${ }^{3}$ DEPARTMENT OF BIOCHEMISTRY, BANAS MEDICAL COLLEGE AND RESEARCH INSTITUTE, PALANPUR, GUJARAT, INDIA \\ ${ }^{4}$ DEPARTMENT OF SURGERY, GMERS MEDICAL COLLEGE, GANDHINAGAR, GUJARAT, INDIA
}

\begin{abstract}
Aim. To evaluate the health-related quality of life (HRQOL) in DFU patients and its association with different surgical parameters in a tertiary care teaching hospital. Methodology. A total of 70 DFU patients from surgery department were enrolled and their demographic details, surgical examination and treatment related parameter were recorded. HRQOL was evaluated using Cardiff Wound Impact Questionnaire. Association of different surgical parameters as predictors of HRQOL was statistically evaluated. Results. Mean age of the study patients was $53.92 \pm 9.27$ with male preponderance and male: female ratio of $1.5: 1$. All the patients in the study suffered from type 2 diabetes and mean duration of the diabetes was $8.0 \pm 1.4$ year. Mean BMI of the study patients was $23.36 \pm 1.4$. All patients of DFU showed deteriorated HRQOL with mean score of $42.2 \pm 15.13$ in social domain, $17.12 \pm 7.43$ in wellbeing, $75.33 \pm 27.06$ in physical domain and total score of $146.56 \pm 45.46$. Increasing age, female gender, increased BMI, alcohol addiction found to be significantly associated with the deteriorated quality of life with respect to all four major domains which include Social life $(\mathrm{P}<0.001)$, wellbeing $(\mathrm{P}<0.07)$, physical symptoms $(\mathrm{P}<0.001)$ and Overall Quality of life $(\mathrm{P}<0.001)$. Surgical parameters like treatment for ulcer, regular follow up, larger size of ulcer, more than one ulcer, and ulcer on planter surface and chronic and recurrent ulcer significantly affect social domain, wellbeing and physical symptoms and total score $(\mathrm{p}<0.05)$. Control of blood sugar levels with non-pharmacological measures, OHA or insulin significantly improve Qol ( $\mathrm{p}<0.05)$. Conclusions. Surgical parameters like site, size, number and duration of ulcer, treatment and blood sugar control significantly affect Qol. Multidisciplinary approach with holistic view is required for management of DFU patients for better quality of life.
\end{abstract}

Category: Original Research Paper

Received: May 31, 2020

Accepted: July 11, 2020

Keywords:

Diabetes foot ulcer, quality of life, Cardiff Wound Impact Questionnaire, surgical parameters

*Corresponding author:

Niyati Lakhani,

Professor and Head, Professor and HOD, Departmen of Surgery, GMERS Medical College, Gandhinagar. Gujarat, India,

E-mail: niyatilakhani2017@gmail.com

\section{Introduction}

Diabetic foot (DF) is one of the most frequent and devastating complications of patients with type 2 diabetes mellitus (T2DM). It constitutes a serious problem for public health systems due to high treatment costs, being one of the principal causes of morbidity, mortality, and disability [1-3]. In addition, it also has a negative impact on quality of life and constitutes a heavy socio-economic burden on the patient and the community, as it involves the risk of extremity loss and therefore usually requires a prolonged hospital stay [4-7].

Diabetic foot occurs in 5\%-10\% of diabetic patients. Uncontrolled hyperglycemia, diabetic neuropathy, peripheral artery disease (PAD), repeated minor traumas, and infection are the main risk factors for the DF ulceration [8-9]. Early diagnosis and efficient treatment strategies are essential to avoid amputation of lower extremity and preserve the quality of life for such patients. Health-related quality of life (HRQoL) assessment can provide a landscape of global health of diabetic patients and lower limb function in particular, which in turn raises patients' awareness of health care and possible outcomes [7]. Earlier studies have revealed that the common surveys used for DF patients are the 36-item short form (SF-36) [8] and foot and ankle ability measure (FAAM) [9]. These studies showed that diabetic foot ulcers negatively affect the patients' perceived Health-Related Quality of Life (HRQoL) due to decreased mobility and consequently the ability to perform daily activities and increasing dependence on others. Moreover, the perceived stress linked to wound healing or re-ulceration and the fear of foot amputation both increase the negative mood and lead to sleep disturbance in patients with diabetic foot ulcers [10-12]. Also, patients with DF 
can thus enter a vicious cycle - the mental stress afforded by physically limiting management strategies designed to facilitate healing of DF wounds or resolution of an active Charcot neuroarthropathy can lead to chronic stress which could potentially negatively influence patient compliance with treatment and thus outcomes. Stress induced immune dysregulation could potentially increase the risk of serious infectious complications of foot ulceration possibly resulting in lower limb amputation [13-15].

Previous studies demonstrated that diabetics with a lower HRQoL score have higher frequency of hospital admission and mortality [16]. Since foot ulceration is a highly preventable complication [17], identifying the role and the predictive value of the risk factors influencing this condition will enable health providers to set up a better management plan to improve their health care. Improving HRQol is recognized as an important outcome measure for a range of interventions, particularly for patients living with chronic conditions. Hence measuring HRQol helps to identify the burden of disease and disability and better monitoring of healthcare objectives. Therefore, there is a need to study disease related parameters, surgical parameters and drug therapy related factors which has major influence on the quality of life of patients in all health domains with DFU which indirectly also affects the process of designing different strategies for prevention and treatment of DFU patients.

\section{Materials and Methods}

\section{Study type}

A cross sectional observational study was performed over a period of one year from July 2018 - August 2019 on patients with diabetic foot visiting the surgery department of a tertiary care hospital in Western India. The study protocol was presented and approved by an Institutional Ethics Committee (IEC). All participants who agreed to participate in this study had signed the written informed consent.

Patients of $>18$ years, both males and females and who received either preventive care or treatment for an active diabetic foot ulcer or protection of a healed ulcer and those who are able to comprehend and complete the questionnaire were enrolled in the study. Patients who were at no current risk of experiencing diabetic foot ulceration, unable to attend the clinic during the study period and having severe cognitive impairment were excluded from the study.

\section{Sample Size and Sampling technique}

Taking into consideration "DFU involves about $15 \%$ of patients with DM during their lives [3]", sample size was calculated by using the formula: $4 \mathrm{pq} / \mathrm{L}^{2}$ (assuming $10 \%$ error and rounding off the value obtained). A sample size of 60 patients was required meeting inclusion and exclusion criteria and attended the surgery department enrolled for the study while taking into considering the dropout rate of $10 \%$ from the questionnaire filling, total 70 patients were enrolled for the study. All patients were diagnosed with type 2 diabetes mellitus (T2DM) and diabetic foot ulcers. A wound was defined using the International Consensus on the Diabetic Foot as a fullthickness wound below the ankle in a diabetic patient, irrespective of the duration, tissue necrosis, and gangrene which was used for clinical diagnosis of DFU.

\section{Data collection}

It was be done by visiting the study participants in the Out-Patient Department or indoor ward of surgery department during study period. After acquiring the study participants, the details regarding the study, namely the purpose of study and the study method was well explained in the vernacular language to each subject. Consent was taken from each subject with an assurance that their identity would not be revealed. All Questionnaires were filled by personal interview.

\section{Measurement Tools and method}

Data was collected using case record form which includes information about patients' demographic characteristics and the factors related to their illness and a separate questionnaire for evaluating the QOL. QOL was assessed using a standardized questionnaire "Cardiff Wound Impact Questionnaire". The "Cardiff Wound Impact (Quality of Life) Questionnaire" was developed to assess HRQol in people with chronic wounds of the lower limbs [6]. Questions were posed to the patients to elicit responses to the 47 screening questions, pertaining to four major domains: 'Social Life' (14 questions graded on a five point -1-good; 5-poor Likert scale), 'Well-Being' (7 questions, graded on a five point Likert scale), 'Physical Symptoms and Daily Living' (24 questions, graded on a five point Likert scale), and 'Overall Quality of Life' (2 questions, graded on a 10 point Likert scale). In the fivepoint Likert scales following response terminology were utilized: 'Not at all/not applicable', 'Slightly', 'Moderately', 'Quite a Bit', and 'Very' [7]. Total screening score was rounded up to 245 points. All scores were calculated and analyzed. The more score denotes more deteriorated quality of life. The score of patients on the basis of Questionnaire was analyzed in a statistical manner.

The questionnaire included the following sociodemographic and economic data: gender, age, if they had a job or unemployed, if they were married or unmarried, living with family or alone, extent of education, comorbidity and income. It also included clinical data related to surgical parameters with respect to: treatment of ulcers, follow up schedule, site of ulcer, ulcer size, duration of ulcer and type of ulcer. In addition to socio-demographic and clinical data, non-pharmacological measures related to wound care and control of diabetes, consumption of Insulin 
and other oral hypoglycemic agents like metformin and sulphonyl urea derivatives were included in questionnaire for analysis of HRQol in patients with chronic wounds due to diabetic foot ulcers.

\section{Statistical Analysis}

Microsoft Excel 2007 and open-Epinfo software were used to analyze the data. Descriptive analysis included actual frequencies, percentage, calculation of means, standard deviations (SD) of categorical variables. The statistical correlations between different determinants (demographic parameters and biochemical parameters) with HRQOL were analyzed using chi-square test, MannWhitney Test and Kruskal Wallis Test as appropriate. The values were considered statistically significant if $\mathrm{P}<0.05$.

\section{Results}

Out of total 70 patients included in the study, only 60 could complete the whole study protocol and QOL questionnaire pertaining to socio-demographic factors, surgical factors and clinical data of drug therapy related factor. It was found that the Mean age of the study patients was $53.92 \pm 9.27$ with male preponderance and male: female ratio of 1.5:1. All patients of DFU showed deteriorated HRQOL with mean score of $42.2 \pm 15.13$ in social domain, $17.12 \pm 7.43$ in wellbeing, $75.33 \pm 27.06$ in physical domain and total score of $146.56 \pm 45.46$. All the patients in the study suffered from type 2 diabetes and mean duration of the diabetes was $8.0 \pm 1.4$ year. Mean BMI of the study patients was $23.36 \pm 1.4$. Baseline demographic parameters have been shown in Table 1. In the multivariate analysis, age remained significantly associated with the quality of life with respect to all four major domains which includes Social life $(\mathrm{P}<0.001)$, wellbeing $(\mathrm{P}<0.07)$, physical symptoms $(\mathrm{P}<0.001)$ and Overall Quality of life $(\mathrm{P}<0.001)$. The results obtained from different age group suffering from diabetic foot ulcers suggest higher prevalence of deterioration of quality of life with increase in age of the patients. On study of gender as a factor affecting quality of life in patients with diabetic foot ulcer it was found that males had significantly lower scores as compared to females in all four major domains indicating better health-related quality of life than females $(\mathrm{P}<0.05)$. Extent of education and BMI were found to be significant factors affecting the quality of life of patients with Diabetic foot in all major domains. Statistical data also reveals that comorbidity and presence of addiction also significantly affects the quality of life with respect to social life domain, physical symptoms and overall quality $(\mathrm{P}<0.05)$ but the domain of wellbeing is non significantly related to addiction in patients ( $\mathrm{P}$ value 0.052).

Surgical parameters like treatment for ulcer affects social domain, wellbeing and physical symptoms and total score $(\mathrm{p}<0.05)$. Regular follow up in the treatment has effect on all the domains of QOL. Site, size, duration and type of ulcer are also associated with one or other domain of quality of life as shown in Table 2. Site of ulcer, i.e. ulcer on planter surface of foot has more deteriorated quality of life as reflected in social domain, physical well-being and total score $(\mathrm{p}<0.05)$. Size of ulcer and duration of ulcer also affects all domains of quality of life $(p<0.05)$; bigger the size and longer the duration, more deteriorated the quality of life. Chronic and recurrent ulcers affect Qol in all domains as compared to acute ulcer $(\mathrm{p}<0.05)$ (Table 2$)$.

Analysis of drug therapy related factors and its association with Qol has been shown in Table 3. Patients following non-pharmacological measures like foot care have better quality of life as compared to those who don't follow such measures as shown in all four domains of quality of life $(p<0.05)$. Patients taking insulin (either as switchover from oral or pre-ulcer treatment) or Oral hypoglycemic drugs (OHA) as drug therapy were found to be significantly affected at all the domains including social, wellbeing, physical symptoms score and overall quality and total score $(\mathrm{p}<0.001)$. This suggests that good control of blood sugar levels either achieved with insulin / OHA / non-pharmacological measures has significantly better quality of life in all domains as shown in Table 3.

Table 1. Demographic details of the study patients and its association with HRQoL: (more score means more deteriorated QOL)

\begin{tabular}{|c|c|c|c|c|c|c|c|c|c|c|c|}
\hline Parameter & No & $\begin{array}{l}\text { social life } \\
\text { domain }\end{array}$ & p-Value & well being & p-Value & $\begin{array}{l}\text { physical } \\
\text { symptoms }\end{array}$ & p-Value & $\begin{array}{l}\text { overall } \\
\text { quality }\end{array}$ & P-Value & total score & p-Value \\
\hline \multicolumn{12}{|c|}{ Age in years } \\
\hline $18-29$ & 2 & $20.1 \pm 5.03$ & $<0.001$ & 0 & 0.07 & 0 & $<0.001$ & $2.1 \pm 1.1$ & $<0.001$ & $40 \pm 23.12$ & $<0.001$ \\
\hline $30-39$ & 9 & $21.2 \pm 9.09$ & & $14.8 \pm 6.50$ & & $43.4 \pm 20.46$ & & $5.8 \pm 1.79$ & & $85.2 \pm 34.67$ & \\
\hline $40-49$ & 18 & $38.85 \pm 13.65$ & & $16.77 \pm 5.0$ & & $67.77 \pm 22.31$ & & $9.11 \pm 2.21$ & & $132.5 \pm 38.77$ & \\
\hline $50-59$ & 26 & $48.38 \pm 11.34$ & & $18.44 \pm 3.07$ & & $86.17 \pm 19.92$ & & $11.17 \pm 3.07$ & & $164.17 \pm 31.89$ & \\
\hline $60-69$ & 5 & $52.55 \pm 15.42$ & & $21.66 \pm 4.21$ & & $92.55 \pm 25.78$ & & $12.77 \pm 2.99$ & & $179.55 \pm 44.55$ & \\
\hline \multicolumn{12}{|l|}{ Gender } \\
\hline Male & 28 & $39.44 \pm 13.22$ & $<0.05$ & $17.29 \pm 5.52$ & $<0.05$ & $71.37 \pm 22.46$ & $<0.05$ & $9.15 \pm 2.78$ & $<0.05$ & $136.69 \pm 40.35$ & $<0.05$ \\
\hline Female & 32 & $48.13 \pm 11.25$ & & $20.33 \pm 4.75$ & & $85.12 \pm 20.14$ & & $12.37 \pm 3.17$ & & $166.15 \pm 45.37$ & \\
\hline \multicolumn{12}{|l|}{ Education } \\
\hline Illiterate & 29 & $57 \pm 12.73$ & $<0.05$ & $23 \pm 1.41$ & 0.265 & $105 \pm 7.07$ & $<0.05$ & $13.33 \pm 1.15$ & $<0.05$ & $196.5 \pm 21.92$ & $<0.05$ \\
\hline
\end{tabular}


Heeya Shah et al.

\begin{tabular}{|c|c|c|c|c|c|c|c|c|c|c|c|}
\hline Up to $10^{\text {th }}$ & 20 & $56.67 \pm 12.70$ & & $21.67 \pm 3.05$ & & $98.67 \pm 11.98$ & & $12.5 \pm 3.45$ & & $\mid 182.33 \pm 26.48$ & \\
\hline Up to $12^{\text {th }}$ & 2 & $52.33 \pm 12.35$ & & $18.83 \pm 3.76$ & & $90.67 \pm 31.77$ & & $11.5 \pm 3.53$ & & $182.33 \pm 46.36$ & \\
\hline Graduate & 6 & $43.75 \pm 14.79$ & & $17.4 \pm 5.40$ & & $77 \pm 24.32$ & & $10.35 \pm 3.45$ & & $148.5 \pm 45.16$ & \\
\hline Postgraduat & 3 & $36.52 \pm 13.93$ & & $17.24 \pm 4.44$ & 0.265 & $65.21 \pm 23.43$ & & $8.76 \pm 2.35$ & & $127.72 \pm 39.11$ & \\
\hline Total & 60 & $42.2 \pm 15.13$ & & $17.87 \pm 4.72$ & & $75.08 \pm 25.43$ & & $9.98 \pm 3.13$ & & $145.13 \pm 44.46$ & \\
\hline \multicolumn{12}{|c|}{ Marital status } \\
\hline Married & 51 & $43.80 \pm 15.43$ & 0.224 & $18.08 \pm 4.71$ & 0.505 & $79.35 \pm 24.38$ & $<0.05$ & $10.27 \pm 3.23$ & 0.339 & $151.51 \pm 43.99$ & 0.059 \\
\hline Unmarried & 2 & $28 \pm 2.83$ & & $20.5 \pm 2.12$ & & $42 \pm 16.97$ & & $9.5 \pm 3.53$ & & $100 \pm 8.48$ & \\
\hline Divorced & 1 & 42.00 & & 15.00 & & 64.00 & & 9.00 & & 130.00 & \\
\hline Widow & 6 & $33.33 \pm 10.82$ & & $15.67 \pm 5.46$ & & $51.67 \pm 18.83$ & & $7.83 \pm 1.32$ & & $108.5 \pm 32.63$ & \\
\hline Total & 60 & $42.2 \pm 15.13$ & & $17.87 \pm 4.72$ & & $75.08 \pm 25.43$ & & $9.98 \pm 3.13$ & & $145.13 \pm 44.45$ & \\
\hline \multicolumn{12}{|l|}{ BMI } \\
\hline$<25$ & 26 & $34.34 \pm 11.35$ & $<0.05$ & $16.14 \pm 2.25$ & 0.246 & $60.35 \pm 24.02$ & $<0.05$ & $8.12 \pm 2.67$ & $<0.05$ & $120.35 \pm 39.33$ & $<0.05$ \\
\hline $25-29.9$ & 26 & $39.5 \pm 14.48$ & & $17.22 \pm 4.70$ & & $71.72 \pm 25.38$ & & $10.39 \pm 3.16$ & & $136.62 \pm 44.84$ & \\
\hline$>30$ & 8 & $45.25 \pm 12.49$ & & $19.35 \pm 7.43$ & & $80.12 \pm 20.22$ & & $11.38 \pm 3.34$ & & $159.28 \pm 64.74$ & \\
\hline Total & 60 & $42.2 \pm 15.13$ & & $17.87 \pm 4.72$ & & $80.08 \pm 25.43$ & & $11.57 \pm 3.13$ & & $155.33 \pm 74.46$ & \\
\hline \multicolumn{12}{|c|}{ Living status } \\
\hline Alone & 9 & $40.89 \pm 13.80$ & 0.781 & $19.44 \pm 5.92$ & 0.281 & $76.33 \pm 29.09$ & 0.875 & $10.89 \pm 3.76$ & 0.351 & $147.56 \pm 47.46$ & 0.861 \\
\hline With & 51 & $42.43 \pm 15.47$ & & $17.59 \pm 4.95$ & & $74.86 \pm 25.05$ & & $9.82 \pm 3.02$ & & $144.70 \pm 44.39$ & \\
\hline Total & 60 & $42.2 \pm 15.13$ & & $17.87 \pm 4.72$ & & $75.08 \pm 25.43$ & & $9.98 \pm 3.13$ & & $145.13 \pm 44.46$ & \\
\hline \multicolumn{12}{|c|}{ Co-morbidity } \\
\hline None & 31 & $19.5 \pm 7.78$ & $<0.05$ & $10.5 \pm 3.54$ & 0.058 & $32 \pm 11.34$ & 0.051 & $5.5 \pm 2.12$ & 0.132 & $67.5 \pm 17.68$ & $<0.05$ \\
\hline HT & 20 & $40.3 \pm 13.22$ & & $17.1 \pm 4.61$ & & $72.2 \pm 23.79$ & & $9.6 \pm 2.98$ & & $139.2 \pm 40.03$ & \\
\hline Cardiovasc & 2 & $46.67 \pm 14.57$ & & $19 \pm 4.23$ & & $80.58 \pm 24.55$ & & $10.58 \pm 3.05$ & & $156.84 \pm 42.49$ & \\
\hline Respiratory & 7 & $34.28 \pm 16.30$ & & $17.14 \pm 5.76$ & & $71.28 \pm 26.72$ & & $9.71 \pm 3.45$ & & $132.43 \pm 47.55$ & \\
\hline Total & 60 & $42.2 \pm 15.13$ & & $17.87 \pm 4.72$ & & $75.08 \pm 25.43$ & & $9.98 \pm 3.13$ & & $145.13 \pm 44.46$ & \\
\hline \multicolumn{12}{|l|}{ Addiction } \\
\hline None & 24 & $51.58 \pm 12.01$ & $<0.001$ & $19.58 \pm 3.87$ & 0.052 & $86.25 \pm 22.16$ & $<0.05$ & $11.96 \pm 3.15$ & $<0.001$ & $169.37 \pm 37.07$ & $<0.001$ \\
\hline Smoking & 26 & $34.31 \pm 13.17$ & & $16.38 \pm 5.40$ & & $65.23 \pm 23.02$ & & $8.46 \pm 2.02$ & & $124.38 \pm 38.78$ & \\
\hline Alcohol & 5 & $49.8 \pm 9.50$ & & $19.6 \pm 3.91$ & & $88.6 \pm 20.95$ & & $11.4 \pm 2.41$ & & $169.4 \pm 31.60$ & \\
\hline Tobacco & 5 & $30.6 \pm 14.13$ & & $15.6 \pm 1.82$ & & $59.2 \pm 32.27$ & & $7 \pm 2.0$ & & $112.4 \pm 49.54$ & \\
\hline Total & 60 & $42.2 \pm 15.13$ & & $17.87 \pm 4.72$ & & $75.08 \pm 25.43$ & & $9.98 \pm 3.13$ & & $145.13 \pm 44.46$ & \\
\hline
\end{tabular}

Table 2: surgical parameters of the study patients and its association with HRQoL: $(n=60)$

\begin{tabular}{|c|c|c|c|c|c|c|c|c|c|c|c|}
\hline Parameters & No & $\begin{array}{l}\text { social life } \\
\text { domain }\end{array}$ & $\mathrm{p}$-Value & well being & p-Value & $\begin{array}{l}\text { physical } \\
\text { symptoms }\end{array}$ & p-Value & $\begin{array}{l}\text { overall } \\
\text { quality }\end{array}$ & p-Value & total score & p-Value \\
\hline \multicolumn{12}{|c|}{ Treatment for ulcer } \\
\hline Yes & 57 & $33.33 \pm 15.27$ & 0.302 & $16 \pm 7.93$ & 0.487 & $45.33 \pm 17.24$ & $<0.05$ & $9.33 \pm 4.62$ & 0.716 & $104 \pm 37.03$ & 0.101 \\
\hline No & 3 & $42.67 \pm 15.11$ & & $17.96 \pm 4.59$ & & $76.65 \pm 24.92$ & & $10.02 \pm 3.09$ & & $147.30 \pm 44.02$ & \\
\hline Total & 60 & $42.2 \pm 15.13$ & & $17.87 \pm 4,72$ & & $75.08 \pm 25.43$ & & $9.98 \pm 3.13$ & & $145.13 \pm 44.46$ & \\
\hline \multicolumn{12}{|c|}{ Regular follow up } \\
\hline Yes & 32 & $34.32 \pm 14.19$ & $<0.001$ & $15.82 \pm 4.49$ & $<0.001$ & $59.03 \pm 19.40$ & $<0.001$ & $8.46 \pm 2.15$ & $<0.001$ & $117.64 \pm 35.39$ & $<0.001$ \\
\hline No & 28 & $49.09 \pm 12.46$ & & $19.66 \pm 4.22$ & & $89.12 \pm 21.61$ & & $11.31 \pm 3.28$ & & $169.19 \pm 37.30$ & \\
\hline Total & 60 & $42.2 \pm 15.13$ & & $17.87 \pm 4.72$ & & $75.08 \pm 25.43$ & & $9.98 \pm 3.13$ & & $145.13 \pm 44.46$ & \\
\hline \multicolumn{12}{|l|}{ Site of ulcer } \\
\hline $\begin{array}{l}\text { Forefoot - } \\
\text { dorsal } \\
\text { surface }\end{array}$ & 31 & $43.5 \pm 21.67$ & $<0.001$ & $19.25 \pm 4.99$ & 0.143 & $76.75 \pm 36.12$ & $<0.05$ & $9.5 \pm 3.87$ & 0.221 & $149 \pm 64.49$ & $<0.05$ \\
\hline $\begin{array}{l}\text { Forefoot - } \\
\text { Planter } \\
\text { surface }\end{array}$ & 4 & $45.74 \pm 13.22$ & & $18.74 \pm 4.62$ & & $79.45 \pm 24.37$ & & $10.45 \pm 3.20$ & & $154.39 \pm 42.05$ & \\
\hline $\begin{array}{l}\text { Midfoot - } \\
\text { dorsal } \\
\text { surface }\end{array}$ & 14 & $19.33 \pm 4.50$ & & $13.67 \pm 4.32$ & & $46.33 \pm 13.12$ & & $7.67 \pm 1.21$ & & $87 \pm 17.75$ & \\
\hline $\begin{array}{l}\text { Midfoot - } \\
\text { Planter } \\
\text { surface }\end{array}$ & 6 & $41.28 \pm 11.77$ & & $17 \pm 4.88$ & & $73.64 \pm 22.34$ & & $9.5 \pm 2.79$ & & $141.43 \pm 34.49$ & \\
\hline $\begin{array}{l}\text { Heel - } \\
\text { Planter } \\
\text { surface }\end{array}$ & 5 & $49.2 \pm 17.06$ & & $18.8 \pm 3.42$ & & $85.2 \pm 27.22$ & & $11.6 \pm 3.91$ & & $164.8 \pm 47.26$ & \\
\hline Total & 60 & $42.2 \pm 15.13$ & & $17.87 \pm 4.72$ & & $75.08 \pm 25.43$ & & $9.98 \pm 3.13$ & & $145.13 \pm 44.46$ & \\
\hline
\end{tabular}




\begin{tabular}{|c|c|c|c|c|c|c|c|c|c|c|c|}
\hline \multicolumn{12}{|c|}{ Ulcer size $\left(\mathrm{cm}^{2}\right)$} \\
\hline$<1$ & 16 & $38.83 \pm 14.59$ & $<0.05$ & $16.33 \pm 5.46$ & 0.240 & $52.5 \pm 19.12$ & $<0.05$ & $10 \pm 3.58$ & $<0.05$ & $117.67 \pm 37.21$ & $<0.05$ \\
\hline $1-5$ & 38 & $39.42 \pm 13.75$ & & $17.42 \pm 4.58$ & & $71.29 \pm 22.03$ & & $9.13 \pm 2.74$ & & $137.26 \pm 39.32$ & \\
\hline$>5$ & 6 & $50.06 \pm 16.53$ & & $19.5 \pm 4.66$ & & $92.56 \pm 25.67$ & & $12 \pm 3.10$ & & $174.12 \pm 46.31$ & \\
\hline Total & 60 & $42.2 \pm 15.13$ & & $17.87 \pm 4.72$ & & $75.08 \pm 25.43$ & & $9.98 \pm 3.13$ & & $145.13 \pm 44.46$ & \\
\hline \multicolumn{12}{|c|}{ Duration of ulcer } \\
\hline$<1$ week & 21 & $20.4 \pm 7.37$ & $<0.001$ & $13.2 \pm 3.63$ & $<0.05$ & $36.2 \pm 11.23$ & $<0.001$ & $5.6 \pm 1.67$ & $<0.001$ & $75.4 \pm 18.72$ & $<0.001$ \\
\hline 1 week to 3 & 34 & $39.70 \pm 13.68$ & & $17.12 \pm 4.30$ & & $72.20 \pm 22.65$ & & $9.65 \pm 2.65$ & & $138.68 \pm 38.23$ & \\
\hline$>3$ months & 5 & $51.43 \pm 11.69$ & & $20.19 \pm 4.55$ & & $89 \pm 21.0$ & & $11.57 \pm 3.04$ & & $172.19 \pm 35.97$ & \\
\hline Total & 60 & $42.2 \pm 15.13$ & & $17.87 \pm 4.72$ & & $75.08 \pm 25.43$ & & $9.98 \pm 3.13$ & & $145.13 \pm 44.46$ & \\
\hline \multicolumn{12}{|c|}{ Type of ulcer } \\
\hline Acute & 42 & $27.83 \pm 14.33$ & $<0.001$ & $14.25 \pm 4.97$ & $<0.05$ & $55.17 \pm 22.05$ & $<0.05$ & $7.33 \pm 1.50$ & $<0.001$ & $104.58 \pm 38.91$ & $<0.05$ \\
\hline Chronic & 6 & $40.67 \pm 6.50$ & & $17.67 \pm 3.72$ & & $70.5 \pm 14.82$ & & $8.5 \pm 0.84$ & & $137.33 \pm 20.12$ & \\
\hline Recurrent & 12 & $46.52 \pm 13.76$ & & $18.93 \pm 14.34$ & & $81.43 \pm 24.76$ & & $10.95 \pm 3.18$ & & $157.83 \pm 41.63$ & \\
\hline Total & 60 & $42.2 \pm 15.13$ & & $17.87 \pm 4.72$ & & $75.08 \pm 25.43$ & & $9.98 \pm 3.13$ & & $145.13 \pm 44.46$ & \\
\hline
\end{tabular}

Table 3: Drug therapy related factors in the study patients:

\begin{tabular}{|c|c|c|c|c|c|c|c|c|c|c|c|}
\hline Parameters & No. & $\begin{array}{l}\text { social life } \\
\text { domain }\end{array}$ & p-Value & well being & p-Value & $\begin{array}{l}\text { physical } \\
\text { symptoms }\end{array}$ & p-Value & $\begin{array}{l}\text { overall } \\
\text { quality }\end{array}$ & p-Value & total score & p-Value \\
\hline \multicolumn{12}{|c|}{ Non pharmacological measures } \\
\hline Yes & 22 & $37.60 \pm 14.23$ & $<0.05$ & $16.37 \pm 3.91$ & $<0.05$ & $64.13 \pm 22.55$ & $<0.001$ & $9 \pm 2.72$ & $<0.05$ & $127.10 \pm 39.14$ & $<0.001$ \\
\hline No & 38 & $50.14 \pm 13.49$ & & $20.45 \pm 4.97$ & & $94 \pm 18.15$ & & $11.68 \pm 3.12$ & & $176.27 \pm 35.36$ & \\
\hline Total & 60 & $42.2 \pm 15.13$ & & $17.87 \pm 4.72$ & & $75.08 \pm 25.43$ & & $9.98 \pm 3.13$ & & $145.13 \pm 44.46$ & \\
\hline \multicolumn{12}{|l|}{ On Insulin } \\
\hline Yes & 24 & $30.29 \pm 11.0$ & $<0.001$ & $15.25 \pm 4.30$ & $<0.001$ & $59.83 \pm 20.39$ & $<0.001$ & $7.37 \pm 1.64$ & $<0.001$ & $112.75 \pm 33.93$ & $<0.001$ \\
\hline No & 36 & $50.14 \pm 12.01$ & & $19.61 \pm 4.20$ & & $85.25 \pm 23.48$ & & $11.72 \pm 2.65$ & & $166.72 \pm 37.10$ & \\
\hline Total & 60 & $42.2 \pm 15.13$ & & $17.87 \pm 4.72$ & & $75.08 \pm 25.43$ & & $9.98 \pm 3.13$ & & $145.13 \pm 44.46$ & \\
\hline \multicolumn{12}{|l|}{ ОНА } \\
\hline None & 2 & $38 \pm 16.97$ & $<0.05$ & $19 \pm 0$ & $<0.05$ & $59 \pm 7.07$ & $<0.05$ & $9.5 \pm 3.54$ & $<0.05$ & $125.5 \pm 27.58$ & $<0.05$ \\
\hline Metformin & 45 & $45.91 \pm 14.37$ & & $18.8 \pm 4.32$ & & $82 \pm 24.25$ & & $10.76 \pm 2.96$ & & $157.47 \pm 41.73$ & \\
\hline $\begin{array}{l}\text { Suphonyl- } \\
\text { urea }\end{array}$ & 1 & 30.00 & & 22.00 & & 30.00 & & 12.00 & & 94.00 & \\
\hline Others & 12 & $30 \pm 11.85$ & & $13.83 \pm 4.69$ & & $55.58 \pm 16.40$ & & $7 \pm 1.95$ & & $106.42 \pm 31.66$ & \\
\hline Total & 60 & $42.2 \pm 15.13$ & & $17.87 \pm 4.72$ & & $75.08 \pm 25.43$ & & $9.98 \pm 3.13$ & & $145.13 \pm 44.46$ & \\
\hline
\end{tabular}

\section{Discussions}

Patient-reported outcomes (PROs) have become an important subject in the area of diabetes-related foot complications. One method of assessing outcomes is the through the use of self-reported health-related quality of life (HRQOL) surveys. These instruments provide a generic measure of overall health (global) and can be disease specific (i.e., diabetes) or even region specific (i.e., lower-extremity function). To date, no metric has demonstrated superiority in assessing the impact of diabetes-related foot complications on HRQOL $[18,19]$.

The demographics characteristics and analysis of health-related quality of life of the study population indicates that all factors such as Age, gender, education and BMI significantly affects the quality of life of patients with higher scores in all 5 domains. The key findings of this study highlight age as important components of HRQoL that affected adversely and magnitude of compromised HRQoL due to the presence of foot ulcer in diabetic patients. This randomized study demonstrated that HRQoL is severely impaired by DFUs in patients with greater age groups $51.6 \%$ with age more than 50 years on all subscales compared to younger patients $[20,21]$. The finding of this study showed that overweight diabetic patients were twice times more likely to develop diabetic foot ulcer as compared with those who had a normal weight due to higher foot pressure in those heavily weighted with higher BMI diabetic patients. Also, obesity and overweight might decrease intensively the normal blood circulation pattern at the lower extremities; as a result, this might lead them to develop diabetic foot ulcer. This is consistent with the study conducted by Nyamu et al [22].

A study conducted on Iranian patients showed that QoL was poorer in women whose body pain was more prominent and level of physical functioning lower with higher level of stress which also corresponds to present study [23]. In the present study, patients with DFU living with family had a worse QoL in all domains. According to Nabuurs-Fransen et al., patients with DFU felt more socially stressed due to lack of executing responsibilities 
[24]. Due to their physical limitations, they had stressed relationships with relatives and friends and reduced participation in social and religious activities. Our results correspond with those of Tenvall, Apelqvist (2000), who confirmed that patients with DFU living together with a partner were evaluated as having a poor QoL [25].

Consumption of alcohol and smoking were other variables which had a strong association with foot ulcers in diabetic patients. It was found that $60 \%$ of patients with diabetic foot ulcers had a history of significantly increased alcohol consumption or smoking since alcohol can be regarded as an aggravating factor for the development of neuropathy that is also reflected by the reduced vibration sense in the ulcer group. It may therefore be assumed that there might be a synergism between a metabolic/diabetic and a toxic/alcoholic neuropathy. Furthermore, the ethyltoxic effect of alcohol impairs the healing process of wounds and therefore promotes foot ulcers. Cigarette smoking is also a positive risk factor for peripheral vascular disease in diabetic patients. Furthermore, smoking is known to enhance diabetic peripheral neuropathy even up to 2-12 times more than that in nonsmokers. The results of our study coincide well to the study performed by Altenburg et al. [26].

The present study also reveals that prevalence of comorbid conditions such as Hypertension, cardiovascular disease and respiratory disease degrades Qol in $48.3 \%$ patients with diabetic foot ulcers. This is in agreement with the study of Doupis et al. [27], who found that hypertension and cardiovascular disease were much more prevalent in diabetic foot disease as hypertension accelerates the development of peripheral vascular disease in certain populations.

Another important observation with respect to ulcer size was, ulcer size $>5 \mathrm{~cm} 2$ was found to have potential negative impact on HRQoL as it was associated with more severe Wagner grade. This could be explained by the fact that the patients with bigger ulcers may not receive better therapeutic equipment (casts or appropriate footwear) resulting in poor everyday functionality. However, differences in scores were only significant for the domains of well-being, physical health and overall quality in this study. Severe Wagner grades with potential negative effect on HRQoL were found in patients with diabetic foot ulcer for more than three months compared to patients with lower duration of disease. These results with respect to surgical parameters like site, size and duration of ulcers were in agreement with study performed by Apelqvist et al. and Glasgov et al. and other literature [28-32]. The finding of this study showed that site $1 \mathrm{a}$ and $3 \mathrm{~b}$ were associated with lower QoL along with chronic ulceration compared to patients with DFU at site $2 \mathrm{~b}$ with acute ulcers. Similar findings have been conveyed by other studies, which found that health-related quality of life scores were significantly poorer for patients with forefoot $(79.9 \%)$ and midfoot $(11.1 \%)$ ulcers [32]. Patients with the principal ulcer on the heel or dorsum of the foot had generally better HRQL than patients with a principal lesion on the toe or plantar area of the foot.

Treatment of ulcer including foot care and nonpharmacological measures showed substantial effect on lowering the Wagners score and improving HRQoL of $36 \%$ of diabetic foot patients. Proper foot care as a nonpharmacological intervention may promote the empowerment of the DFU patients and hence the, subjectively assessed, HRQoL. According to Elvin-Lewis [33] "for a variety of reasons more individuals are now-adays preferring to take personal control over their health, not only in the prevention of diseases through better foot care but also to treat them". Diabetes Treatment Satisfaction is a method to assess HRQoL that was designed explicitly to measure issues of importance to patients and therefore it was significant to assess different drug therapy. The Diabetes Treatment Satisfaction Questionnaire is highly sensitive to major changes in treatment, for example, from OHA to Insulin injections or from conventional (more rigid insulin regimen with fixed meal times) to a more flexible insulin dosing (allowing for dietary freedom). It is seen that treatment satisfaction score correlates improve HRQoL of $40 \%$ diabetic foot patients with reduced duration of disease and perceived blood glucose control which was consistent with study performed by Lewis et al. [34]. It is widely recommended that blood glucose be optimized to improve wound healing and limit adverse effects on cellular immunity and infection. Another Cochrane review assessing effects of glycemic targets in type 2 diabetes found that those with intensive glycemic control had a $35 \%$ reduction in risk of lowerextremity amputation which coincided with results of the present study indicating a better QoL in patients with insulin or OHA therapy [35].

This study was one of its initial types in India for evaluation of quality of life in diabetes foot ulcer patients including all five major domains like well-being, social, physical symptoms, overall and total score. Also, present study focused on addressing all aspects of the diabetic foot which was best accomplished by the multidisciplinary team to overcome complications related to heterogeneity of the study due to diverse DFU patients. The limitation of our study was relatively small sample size, and single study site. It has been noted that the HRQoL of people with diabetic ulceration and their families or caregivers has been significantly affected in all aspects. The few available studies indicate that the everyday experiences of such patients may be even poorer than those of patients who have had an amputation. There are many instruments used to measure HRQoL. Several are specific to diabetic foot ulceration, and are very useful in assessing the overall 
wellbeing of patients and, in some cases, their caregivers. Management of diabetic foot ulcers requires effective treatment and patient compliance in order to promote wound healing; in turn, improving people's lifestyles and QoL. It is evident from the literature that there have only been relatively small studies conducted in relation to the QoL of people with a diabetic foot ulcer. Large-scale studies are further required to examine how significant diabetic foot ulceration really is, and to establish if whether additional support is required for this group to improve quality of life.

\section{Conclusions}

The health-related quality of life experiences of patients with diabetic foot ulceration have received little attention. This article has reported that coping with a diabetic foot ulcer is a traumatic time for people and their families and caregivers. This study has identified different risk factors and surgical parameters affecting QoL. Demographic parameters like increasing age, female gender, higher BMI and alcohol addiction deteriorates QoL. Surgical parameters like regular treatment of ulcer a follow up, foot care advice followed by patients, ulcer size, site and chronicity affect QoL. Overall glucose level control either with insulin or OHA or both can improve Qol in DFU patients. It is therefore essential that healthcare professionals realize that when treating an individual with a diabetic foot ulcer, a holistic approach is required to assess the overall impact of chronic ulceration and treating it with a multidisciplinary approach. The study findings have implications for clinical and policy decisions, as well as for the foundation and design for future studies with larger sample sizes. In particular, our findings underscore the importance of health-related quality of life, treatment satisfaction, and an integrated therapeutic approach in the management of patients with diabetes foot ulcers.

\section{Conflict of interest disclosure}

There are no known conflicts of interest in the publication of this article. The manuscript was read and approved by all authors.

\section{Compliance with ethical standards}

Any aspect of the work covered in this manuscript has been conducted with the ethical approval of all relevant bodies and that such approvals are acknowledged within the manuscript.

\section{References}

1. Wild S, Roglic G, Green A, Sicree R, King H. Global prevalence of diabetes: estimates for the year 2000 and projections for 2030. Diabetes Care. 2004;27(5):10471053. doi:10.2337/diacare.27.5.1047
2. Matricali GA, Dereymaeker G, Muls E, Flour M, Mathieu C. Economic aspects of diabetic foot care in a multidisciplinary setting: a review. Diabetes Metab Res Rev. 2007;23(5):339-47. doi: 10.1002/dmrr.706

3. Rodríguez Bolaños Rde L, Reynales Shigematsu LM, Jiménez Ruíz JA, Juárez Márquezy SA, Hernández Ávila M. Costos directos de atención médica en pacientes con diabetes mellitus tipo 2 en México: análisis de microcosteo [Direct costs of medical care for patients with type 2 diabetes mellitus in Mexico micro-costing analysis]. Rev Panam Salud Publica. 2010; 28(6): 412-420. doi: 10.1590/s102049892010001200002

4. Peters EJ, Lavery LA, Armstrong DG. Diabetic lower extremity infection: influence of physical, psychological, and social factors. $J$ Diabetes Complications. 2005;19(2):107-112. doi:10.1016/j.jdiacomp.2004.06.002

5. Goodridge D, Trepman E, Sloan J, et al. Quality of life of adults with unhealed and healed diabetic foot ulcers. Foot Ankle Int. 2006; 27(4): 274-280. doi:10.1177/107110070602700408

6. Neville RF, Kayssi A, Buescher T, Stempel MS. The diabetic foot. Curr Probl Surg. 2016;53(9):408-437. doi:10.1067/j.cpsurg.2016.07.003

7. Rathur HM, Boulton AJ. The diabetic foot. Clin Dermatol. 2007;25(1):109-120.

8. Alexiadou K, Doupis J. Management of diabetic foot ulcers. Diabetes Ther. 2012; 3(1): 4. doi: 10.1007/s13300-012-0004-9

9. Fawzy MS, Alshammari MA, Alruwaili AA, et al. Factors associated with diabetic foot among type 2 diabetes in Northern area of Saudi Arabia: a descriptive study. BMC Res Notes. 2019;12(1):51. Published 2019 Jan 22. doi:10.1186/s13104-019-4088-4

10. Kinmond K, McGee P, Gough S, Ashford R. 'Loss of self': a psychosocial study of the quality of life of adults with diabetic foot ulceration [published correction appears in J Tissue Viability. 2003 Apr;13(2):80]. J Tissue Viability. 2003;13(1):6-16. doi:10.1016/s0965206x(03)80025-6

11. Ragnarson Tennvall G, Apelqvist J. Health-economic consequences of diabetic foot lesions. Clin Infect Dis. 2004;39 Suppl 2:S132-S139. doi:10.1086/383275

12. Ragnarson Tennvall G, Apelqvist J. Health-economic consequences of diabetic foot lesions. Clin Infect Dis. 2004;39 Suppl 2:S132-S139. doi:10.1086/383275

13. Yotsu RR, Pham NM, Oe M, et al. Comparison of characteristics and healing course of diabetic foot ulcers by etiological classification: neuropathic, ischemic, and neuro-ischemic type. $J$ Diabetes Complications. 2014;28(4):528-535. doi: 10.1016/j.jdiacomp.2014.03.013 
14. Yazdanpanah L, Nasiri M, Adarvishi S. Literature review on the management of diabetic foot ulcer. World J Diabetes. 2015;6(1):37-53. doi:10.4239/wjd.v6.i1.37

15. Lipsky BA, Berendt AR, Cornia PB, et al. 2012 Infectious Diseases Society of America clinical practice guideline for the diagnosis and treatment of diabetic foot infections. Clin Infect Dis. 2012; 54(12):e132-e173. doi:10.1093/cid/cis346

16. Wukich DK, Raspovic KM. Assessing Health-Related Quality of Life in Patients With Diabetic Foot Disease: Why Is It Important and How Can We Improve? The 2017 Roger E. Pecoraro Award Lecture. Diabetes Care. 2018;41(3):391-397. doi:10.2337/dci17-0029

17. Al-Rubeaan K, Al Derwish M, Ouizi S, et al. Diabetic foot complications and their risk factors from a large retrospective cohort study. PLoS One. 2015; 10(5): e0124446. doi:10.1371/journal.pone.0124446

18. Tang TS, Yusuf FLA, Polonsky WH, Fisher L. Assessing quality of life in diabetes: II - Deconstructing measures into a simple framework. Diabetes Res Clin Pract. 2017;126:286-302. doi:10.1016/j.diabres.2016.10.007

19. Fisher L, Tang T, Polonsky W. Assessing quality of life in diabetes: I. A practical guide to selecting the best instruments and using them wisely. Diabetes Res Clin Pract. 2017;126:278-285. doi:10.1016/j.diabres.2016.10.018

20. Nabuurs-Franssen MH, Huijberts MS, Nieuwenhuijzen Kruseman AC, Willems J, Schaper NC. Health-related quality of life of diabetic foot ulcer patients and their caregivers. Diabetologia. 2005;48(9):1906-1910. doi: 10.1007/s00125-005-1856-6

21. Sekhara MS, Unnikrishnana MK, Vijayanarayanaa K, Rodriguesb GS. Impact of patient-education on health related quality of life of diabetic foot ulcer patients: A randomized study. Clinical Epidemiology and Global Health 2019; 7(3): 382-388. doi: 10.1016/j.cegh.2018.07.009

22. Nyamu PN, Otieno CF, Amayo EO, McLigeyo SO. Risk factors and prevalence of diabetic foot ulcers at Kenyatta National Hospital, Nairobi. East Afr Med J. 2003;80(1):36-43. doi:10.4314/eamj.v80i1.8664

23. Sanjari M, Safari S, Shokoohi M, et al. A crosssectional study in Kerman, Iran, on the effect of diabetic foot ulcer on health-related quality of life. Int J Low Extrem Wounds. 2011;10(4):200-206. doi: $10.1177 / 1534734611428728$

24. Ragnarson Tennvall G, Apelqvist J. Health-related quality of life in patients with diabetes mellitus and foot ulcers. J Diabetes Complications. 2000;14(5):235-241. doi:10.1016/s1056-8727(00)00133-1
25. Walsh JW, Hoffstad OJ, Sullivan MO, Margolis DJ. Association of diabetic foot ulcer and death in a population-based cohort from the United Kingdom. Diabet Med. 2016; 33(11): 1493-1498. doi: 10.1111/dme. 13054

26. Altenburg N, Joraschky P, Barthel A, et al. Alcohol consumption and other psycho-social conditions as important factors in the development of diabetic foot ulcers. Diabet Med. 2011;28(2):168-174. doi: 10.1111/j.1464-5491.2010.03151.x

27. Alexiadou K, Doupis J. Management of diabetic foot ulcers. Diabetes Ther. 2012;3(1):4. doi: 10.1007/s13300-012-0004-9

28. Apelqvist J, Larsson J, Agardh CD. Long-term prognosis for diabetic patients with foot ulcers. J Intern Med. 1993; 233(6): 485-491. doi:10.1111/j.13652796.1993.tb01003.x

29. Glasgow RE, Ruggiero L, Eakin EG, Dryfoos J, Chobanian L. Quality of life and associated characteristics in a large national sample of adults with diabetes. Diabetes Care. 1997;20(4):562-567. doi: 10.2337/diacare.20.4.562

30. van Baal J, Hubbard R, Game F, Jeffcoate W. Mortality associated with acute Charcot foot and neuropathic foot ulceration. Diabetes Care. 2010;33(5):1086-1089. doi: 10.2337/dc09-1428

31. Boutoille D, Féraille A, Maulaz D, Krempf M. Quality of life with diabetes-associated foot complications: comparison between lower-limb amputation and chronic foot ulceration. Foot Ankle Int. 2008;29(11): 1074-1078. doi:10.3113/FAI.2008.1074

32. Carrington AL, Mawdsley SK, Morley M, Kincey J, Boulton AJ. Psychological status of diabetic people with or without lower limb disability. Diabetes Res Clin Pract. 1996; 32(1-2): 19-25. doi: 10.1016/01688227(96)01198-9

33. Elvin-Lewis M. Should we be concerned about herbal remedies. J Ethnopharmacol. 2001;75(2-3):141-164. doi:10.1016/s0378-8741(00)00394-9

34. Lewis KS, Bradley C, Knight G, Boulton AJ, Ward JD. A measure of treatment satisfaction designed specifically for people with insulin-dependent diabetes. Diabet Med. 1988;5(3):235-242. doi:10.1111/j.14645491.1988.tb00976.x

35. Hemmingsen B, Lund SS, Gluud C, et al. Targeting intensive glycaemic control versus targeting conventional glycaemic control for type 2 diabetes mellitus. Cochrane Database Syst Rev. 2013;(11):CD008143. doi:10.1002/14651858.CD008143.pub3 